ISAHP 2003, Bali, Indonesia, August 7-9, 2003

\title{
SELECTING A SUITABLE LOCATION FOR WOOD INDUSTRY UNITS
}

\author{
Majid Azizi ${ }^{1}$ \\ Natural Resources Faculty, \\ University of Tehran \\ mazizi@chamran.ut.ac.ir \\ Mohammad Modarres \\ Department of Industrial Engineering, \\ Sharif University of Technology \\ modarres@sharif.edu \\ Saeed Amiri \\ Natural Resources Faculty \\ University of Tehran
}

Keywords: decision, location, priority, criteria, hierarchy

Summary: The objective of this paper is to develop a method for selecting the best location for establishing a wood industry unit. The decision making is examined within the framework of benefits, opportunities, costs, and risks (BOCR), called the merits of the decision. A hierarchy is developed to prioritize the BOCR themselves and Analytic Hierarchy Process ratings approach is applied to evaluate this hierarchy. It is recognized that benefits, opportunities, costs and risks are often not emphasized equally when making a decision. In fact, it is vital to design a decision supporting system to evaluate them in terms of the values of the decision-making person or organization. A control hierarchy is then created and prioritized using the AHP to evaluate the "control criteria" of the system. There are a total of 18 control criteria in the system and each controls a decision network evaluated using the Analytic Network Process (ANP). We apply this method for a real case in Iran. There are six potential locations, or in fact the alternatives of the decision networks. The final synthesis of the system shows Baneh in the province of Kurdestan is the best choice.

\section{Introduction}

In this article, we apply AHP(Saaty,1999) and ANP(Saaty, 2001a) as the tools for our decision about where to establish plywood and veneer units in Iran. There are regions in Iran rich in potential for the establishment of wood industry (plywood and veneer) units. In the northern parts of Iran there are spreadleaf forests and in the northwestern and western parts of Iran there are rich poplar tree resources. There are six places in Iran suitable for the plywood and veneer industry. To choose the best one, we applied the ANP method. The six potential sites are the cities of Baneh in the province of Kurderstan, Boukan in the province of West Azerbaijan, Rezvanshahr in the province of Gilan, Fouman in the province of Gilan, Shabestar in the province of East Azerbaijan, and Uromiyeh in the province of West Azerbaijan.

These provinces were studied in depth and their wood resources, particularly forest wood and poplar, were estimated. For the industrial investor this choice of where to establish plywood and veneer units is of great importance. In macro-decision making such as selecting a best site for locating a factory in a country, the best approach is to divide the criteria into favorable and unfavorable. The person making the decision will

1 - Special thanks goes to Professor Saaty T., Rozann W. Saaty, Ms. Yeonmin Cho, and their colleagues at of Katz Business School of Pittsburgh University, who helped me to prepare this research.

Proceedings $-7^{\text {th }}$ ISAHP 2003 Bali, Indonesia 
consider the favorable criteria as benefits and the unfavorable criteria as costs. There are also possible events that may happen as well, which may be considered positive or negative and these are divided into opportunities criteria and risks criteria (Saaty,2001a). One example by Saaty of this type of decision structure is given in the book The Analytic Network Process, related to the issue of the USA Congress deciding whether to establish commercial ties with China or not (Saaty and Cho, 2001b), where Preferred Normal Trade Relations (PNTR) was the best choice.

\section{Materials and Methods}

In this research the merits of benefits, costs, opportunities, and risks are influenced by general factors(Saaty and Cho, 2001b). These factors may be described as falling into the following broad categories:

-Environmental factors related to forest reclamation and wood agronomy issues.

-Social factors related to such issues as population growth and literacy level.

-Economic factors related to economic issues.

The hierarchy to prioritize the merits of benefits, opportunities, costs, and risks by rating them is shown in Fig. 1(Haksever et al 1990; Krajewski and Ritzman, 1999; Chase, Aquilano and Jacobs, 1998). Each of the lowest level criteria has five possible ratings ranging from very high to very low. The BOCR are each rated by choosing its appropriate rating for each lowest level criterion and summing in the usual way(Saaty, 2001a). The resulting normalized priorities for the BOCR sum to 1 .

\subsection{Benefits to producers or investors}

- Good business climate

- Quality of labor

- Infrastructure

- Natural Resources

- Suppliers

- $\quad$ Sales(proximity to market)

\subsection{Costs to producers or investors}

- Distribution/transportation

- Land /construction

- Labor costs

- Living costs

- Purchase of raw material

- Political / cultural conflicts

\subsection{Opportunities for producers or investors}

- Expansion of the industry

- Community development

- Future investment

\subsection{Risks for producers and investors}

- Unreliability of raw material supply

- lack of financial support

- Lack of suitable markets

The Analytical Network Process (ANP), a generalization of the Analytic Hierarchy Process (AHP) method for multicriteria decision making, provides an even broader framework for decision making in complicated environments. The following are some of the features of the ANP that distinguish it from the AHP(Saaty, 2001c):

--Rather than a hierarchy, the basic structure of a network consists of clusters and nodes and logical connections between them. The judgment process is carried out by creating matrices of pairwise comparison judgments for nodes in a cluster linked to the same parent node. 
--Sub-networks can be created for and attached to nodes in a network, and they subnetworks have the same structure as any network. There can be many layers of sub-networks. The subnetworks at the bottom contain the alternatives of the decision.

--Supermatrices are created in the sub-networks and the results integrated with the higher levels of networks.

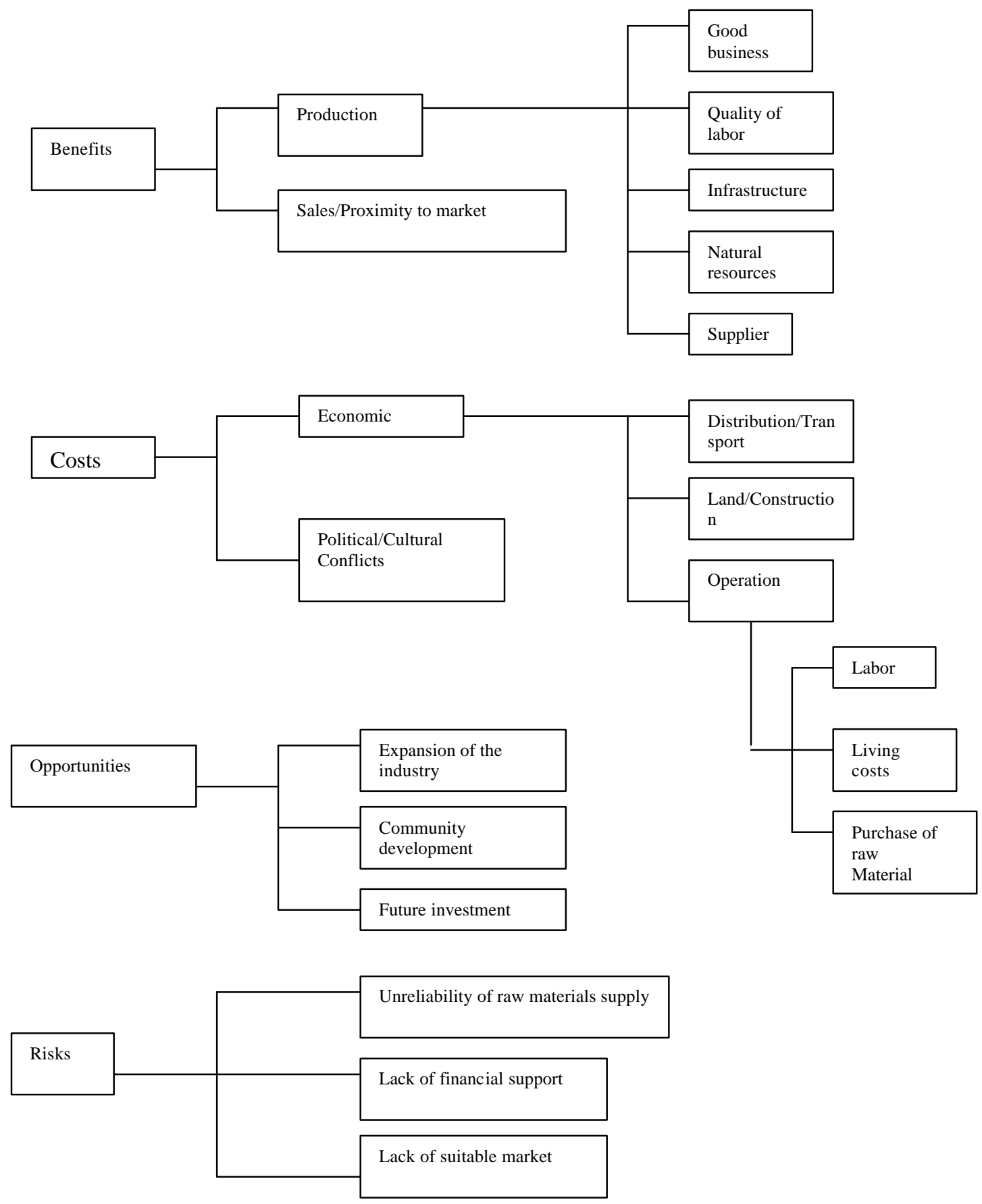

Figure 1. Hierarchy for Rating the BOCR Merits 
--Decisions are most generally approached by breaking them up into merits: benefits, costs, opportunities, risks. For each merit a sub-network is created with control criteria, and for these control criteria in turn decision sub-networks are created containing the alternatives of the decision.

--When costs and risks are being evaluated, the analysis is done from the perspective of which is more costly or more risky, so that reciprocals of the results are used in synthesizing the results for the final answer.

--A formula is used to combine the results for the BOCR merits.

--Four hierarchies were designed for the four merits of benefits, costs, opportunities, and risks. Each hierarchy includes objective (benefits, costs, opportunities, and risks), related sub-criteria, and candidate choices for priorities.

--Two-by-two comparisons were done for each one of the above hierarchy. Weights of sub-criteria and choices are obtained(in this case the weights of choices are calculated from the weights of merits of costs and risks with regard to the reciprocal analysis ).

-Upon the determination of merits of costs, benefits, opportunities, and risks in the first stage, and then their integration into the obtained weights for the choices in the previous stage, and the priorities are set for the choices.

--In BOCR structure the following formula is used in calculations(Saaty, 2001c):

$\$ p($ Benefits $) * \$\{$ Benefits $\}+\$ p($ Costs $) * \$\left\{\right.$ Costs $\left.{ }^{\wedge}-1\right\}+$

$\$ p$ (Opportunities) *\$\{Opportunities\} + \$p (Risks)*\$ Risks^-1\}

--To apply the ANP method, the Super Decisions Software was used .

\section{Results}

The results of the influence of the overall factors on the merits of benefits, costs, opportunities, risks, and the rate of priority of the above mentioned merits are reported in Table 1.

The findings reported in Table 1 show that opportunities at 0.354 and benefits at 0.346 have a higher priority in this decision than costs and risks. The purpose of rating the BOCR this way is to link an individual's or organization's overriding or superior values that remain relatively independent from one decision to another with the results of the model of factors related specifically to that decision.

The priorities of the criteria in the four hierarchies of benefits, costs, opportunities and risks obtained in the usual AHP way by pairwise comparing the sub-criteria and choices against each one of the above mentioned merits are reported in Table 2.

Table 1. Priority rating for the merits: Benefits, Costs, Opportunities and Risks

very high(1),high(0.51), medium(0.252), low(0.124),very low(0.065)

\begin{tabular}{|c|c|c|c|c|}
\hline & Benefits & Costs & Opportunities & Risks \\
\hline Economic $(0.211)$ & very high & high & very high & high \\
\hline \multicolumn{5}{|l|}{ Environmental(0.705) } \\
\hline Forest reclamation $(0.25)$ & very high & low & very high & high \\
\hline Wood agronomy(0.75) & very high & medium & very high & high \\
\hline \multicolumn{5}{|l|}{ Social $(0.084)$} \\
\hline Population growth(0.8) & low & very high & medium & low \\
\hline Literacy level(0.2) & medium & low & very high & very low \\
\hline Overall Priorities & 0.346 & 0.123 & 0.354 & 0.177 \\
\hline
\end{tabular}

Proceedings $-7^{\text {th }}$ ISAHP 2003 Bali, Indonesia 
The findings reported in Table 2 show that the choice of Baneh city is of the highest priority in terms of criteria of benefits and opportunities and the choice of Rezvanshahr city is again of the highest priority in terms of criteria of costs and risks.

Final priority establishment of the choices which is obtained from the integration of the weights of the merits of benefits, costs, opportunities, and risks and the weights of choices against the above mentioned merits are reported in Table 3.

Table 2. Synthesized Priorities of the 18 Criteria and Subcriteria with the Results from the Decision Sub-networks

\begin{tabular}{|c|c|c|c|c|c|c|c|c|c|}
\hline Merits & \multicolumn{2}{|c|}{ criteria } & subcriteria & Baneh & Boukan & Fouman & Uromiyeh & Rezvanshahr & Shabestar \\
\hline \multirow{11}{*}{$\begin{array}{l}\text { Benefits } \\
(0.346)\end{array}$} & \multirow{2}{*}{\multicolumn{2}{|c|}{$\begin{array}{l}\text { Production } \\
(0.875)\end{array}$}} & Good business & 0.251 & 0.1 & 0.059 & 0.383 & 0.045 & 0.159 \\
\hline & & & $(0.048)$ & & & & & & \\
\hline & & & Infrastructure & 0.382 & 0.25 & 0.064 & 0.159 & 0.043 & 0.1 \\
\hline & & & $(0.207)$ & & & & & & \\
\hline & & & Natural resources & 0.383 & 0.25 & 0.064 & 0.159 & 0.043 & 0.1 \\
\hline & & & $(0.604)$ & & & & & & \\
\hline & & & Quality of labor & 0.043 & 0.064 & 0.25 & 0.1 & 0.383 & 0.159 \\
\hline & & & $(0.029)$ & & & & & & \\
\hline & & & Supplier & 0.383 & 0.25 & 0.043 & 0.159 & 0.064 & 0.1 \\
\hline & & & $(0.111)$ & & & & & & \\
\hline & \multicolumn{3}{|c|}{$\begin{array}{l}\text { Sales/Proximity to market } \\
(0.125)\end{array}$} & 0.1 & 0.043 & 0.383 & 0.159 & 0.064 & 0.25 \\
\hline \multicolumn{4}{|c|}{ Benefits Synthesized } & 0.333 & 0.2124 & 0.1062 & 0.167 & 0.056 & 0.123 \\
\hline \multicolumn{4}{|c|}{ Benefits Normalized } & 0.334 & 0.2129 & 0.1064 & 0.167 & 0.056 & 0.123 \\
\hline \multirow{3}{*}{\multicolumn{2}{|c|}{$\begin{array}{l}\text { Opportunities } \\
(0.354)\end{array}$}} & \multicolumn{2}{|c|}{ Community development } & 0.382 & 0.25 & 0.043 & 0.159 & 0.064 & 0.1 \\
\hline & & \multicolumn{2}{|c|}{$\begin{array}{l}\text { Expansion of Industry } \\
(0.2176)\end{array}$} & 0.042 & 0.064 & 0.382 & 0.1 & 0.25 & 0.159 \\
\hline & & \multicolumn{2}{|c|}{$\begin{array}{l}\text { Future Investment } \\
(0.0914)\end{array}$} & 0.042 & 0.064 & 0.25 & 0.1 & 0.159 & 0.382 \\
\hline \multicolumn{4}{|c|}{ Opportunities Synthesized } & 0.276 & 0.192 & 0.135 & 0.139 & 0.113 & 0.137 \\
\hline \multicolumn{4}{|c|}{ Opportunities Normalized } & 0.278 & 0.193 & 0.136 & 0.14 & 0.1138 & 0.138 \\
\hline
\end{tabular}


Table 2 (Continued)

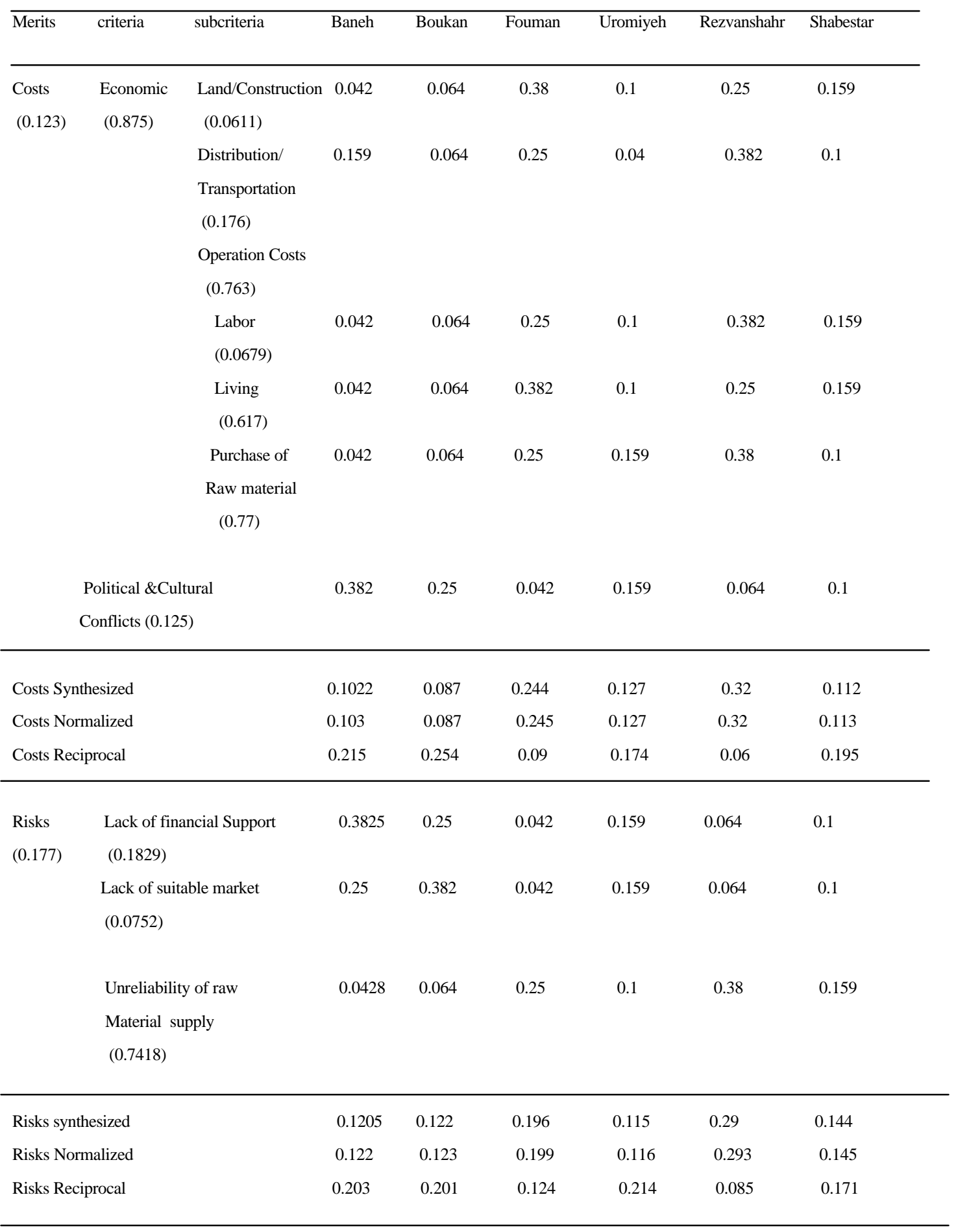


Table 3

Final synthesis of alternatives priorities

\begin{tabular}{lccccc}
\hline & $\begin{array}{c}\text { Benefits } \\
(0.346)\end{array}$ & $\begin{array}{c}\text { Opportunities } \\
(0.354)\end{array}$ & $\begin{array}{c}\text { Costs } \\
(0.123)\end{array}$ & $\begin{array}{c}\text { Risks } \\
(0.177)\end{array}$ & $\begin{array}{c}\text { Final Outcome } \\
\text { Additive }\end{array}$ \\
\hline Baneh & 0.334 & 0.278 & 0.215 & 0.203 & 0.276 \\
Boukan & 0.2129 & 0.193 & 0.254 & 0.201 & 0.209 \\
Fouman & 0.1064 & 0.136 & 0.09 & 0.124 & 0.118 \\
Uromiyeh & 0.167 & 0.14 & 0.174 & 0.214 & 0.167 \\
Rezvanshahr & 0.056 & 0.1138 & 0.06 & 0.085 & 0.082 \\
Shabestar & 0.123 & 0.138 & 0.195 & 0.171 & 0.146 \\
\hline
\end{tabular}

Findings reported in Table 3 show that the choice of Baneh city in the province of Kurdestan has the highest priority, and is the most suitable place to establish plywood and veneer units.

With regard to the criteria of benefits and opportunities, which are the favorable criteria in decision making, Baneh has the highest priority. After Baneh, Bukan city in West Azerbaijan has gained the second priority for establishment of plywood and veneer units. The third, fourth, fifth, and sixth priorities are Uromiyeh, Shabestar, Fouman, and Rezvanshahr.

Findings from sensitivity analysis at the BOCR level were obtained using the Super Decision Software for the merits of benefits, costs, opportunities, and risks, as shown in Appendices.

\section{Conclusion}

As shown in Table 1, opportunities and benefits are more important in the decision compared with costs and risks as they have more weight: Opportunities $=0.354$, Benefits $=0.346$

Concerning the best choice under benefits and opportunities, as shown in Table 2, the cities of Baneh and Bukan are first and second respectively. The reasons are that with regard to benefits, Baneh city is absolutely preferred over the other choices because of the three sub-criteria of supplies of raw materials, natural resources, and infrastructure.

It has rich resources of raw materials (poplar tree). Baneh city is also preferred under opportunities because of how it ranks terms of the sub-criterion of community development (Table 2). In other words establishing plywood and veneer units in this region will bring more development, because of the level of nondevelopment in this region.

Bukan is the second choice after the city of Baneh in terms of benefits under the three sub-criteria of natural resources, suppliers of raw materials, and infrastructure. See Table 2. It has rich resources of raw materials (particularly the poplar tree). With respect to opportunities Bukan city, after Baneh, has the highest priority, again because of the community development criterion. 
Priority determination of the merits of costs, risks show that Baneh is of the fifth priority(Table 2). The reason for this can be described as follows: 1

Among the sub-criteria of costs, the choice of Baneh city is of the absolute priority over the other choices only in terms of sub-criterion of cultural and political conflicts.

In another word if the plywood and veneer units are operated, the choice of Baneh city shall be of the highest non-desirability for the decision makers and investors over the other choices in terms of the existence of political and cultural conflics. While in terms of sub-criteria related to costs, Baneh city shall be of less non-desirability over the other choices. About the sub-criteria related to risks, the choice of Baneh city is of absolute priority for the decision makers and investors only in terms of lack of financial support. In other words, if the plywood and veneer units are established, the choice of Baneh shall be of less desirability in terms of financial support, and this is due to the proximity of this city to the border and security issues. While contrary, in terms the important sub-criterion of unreliability of the raw materials supply, this choice shall likely be of the least non-desirability for the investors and decision makers , and this is because the region has a high potential in terms of existence of raw materials.

About the criteria of costs, risks, like Baneh, Bukan is of low priority(Table2), and in terms of sub-criteria of costs, the choice of Bukan has conditions similar to that of Baneh, in such a way that this choice, after Baneh, has priority over the other choices in terms of political and cultural conflicts, but in terms of other sub-criteria of costs, this choice is of less non- desirability over the other choices.

About the sub-criteria related to risks, Bukan is of the absolute priority solely in terms of the sub-criterion of lack of suitable market. In other words, if the plywood and veneer units are established, then the choice of Bukan is considered as the less priority by the decision makers and investors in terms of suitable market, and this is due to its far from main sales centers which are the consumers of plywood and veneer, and are usually located in Tehran and the cities around it, while in terms of important sub-criterion of reliability of supply of the raw materials, the choice of Bukan shall be of the least non-desirability for investors and decision makers after the choice of Baneh.

\subsection{Sensitivity Analysis at the level of BOCR}

Since there may be different judgements on the comparison of priority rates of benefits, opportunities, costs, and risks or their sub-criteria, to achieve stability and compatibility of the analysis, we apply sensitivity analysis (Saaty, 2001c).

About the findings of BOCR hierarchy, by increasing or decreasing one of the criteria, we will find that the ratios of other criteria do not change. For example if the benefit weights increases from 0.346 to 0.5 the sum of other criteria will be equal to 0.5 and the proportion between them will remain consistent and the new weights of other criteria be as follows:

Opportunities: 0.271, Costs:0.094, Risks:0.135

In this study we found that with the increase or decrease in the weights of benefits and opportunities, there will no change in the establishments of priority for the BOCR conclusions (Figures 2,4), but with the increase in costs and risks, establishment of priority will change and then it will influence the findings.

About the costs: Whenever the weight of costs increase from 0.123 to 0.49 , there will be some change in the establishment of priorities for the choices of Uromiyeh and Shabestar, in such a way that at this point Shabestar is the third and Uromiyeh will be the forth priority. The more the increase, the more this difference. The second change will happen with the increase in costs from 0.123 to 0.63 , in such a way that the establishment of priority for the choices of Baneh and Bukan will change. And Bukan will be the first priority and Baneh the second priority, if this increase in costs continues, this difference will again be greater(Figure 3).

If the weights of risks increase from 0.177 to 0.79 , then the priorities for Uromiyeh and Bukan will change. Uromiyeh will be the second priority and Bukan the third. If the increase in risks continues up to 0.92, then Uromiyeh will be the firstpriority,Baneh the second and Bukan the third priority (Figure 5 ). 
Figure 3: Sensitivity Analysis of Costs

Figure 2: Sensitivity Analysis of Benefits

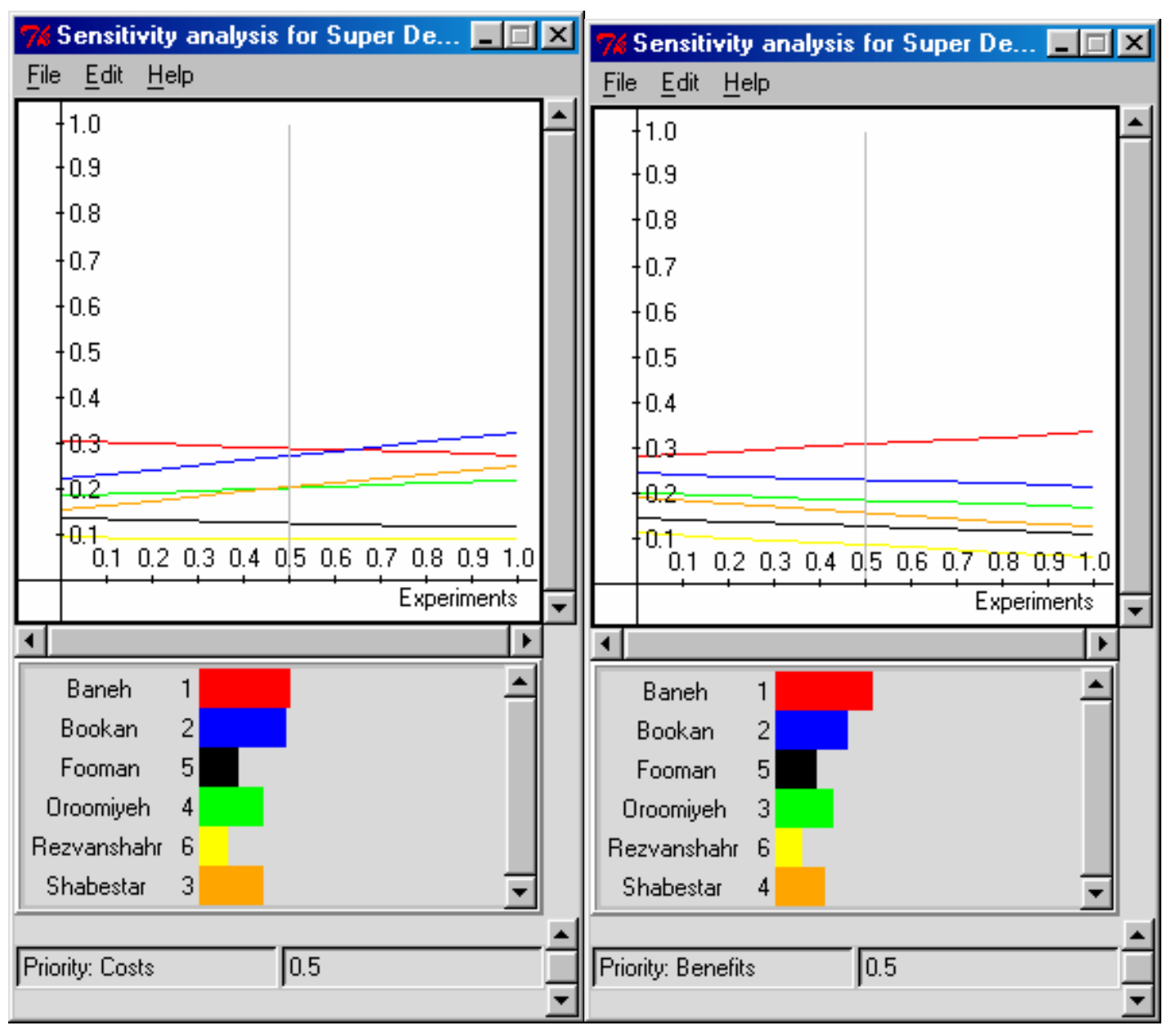


Figure 5: Sensitivity Analysis of Risks

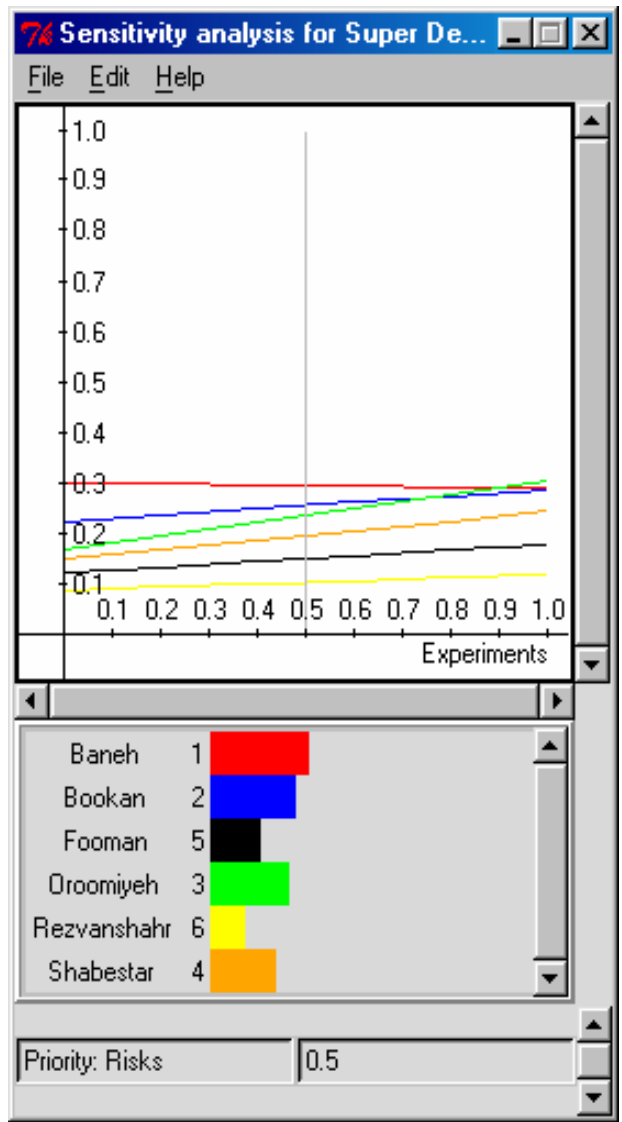

Figure 4: Sensitivity Analysis of Opportunities

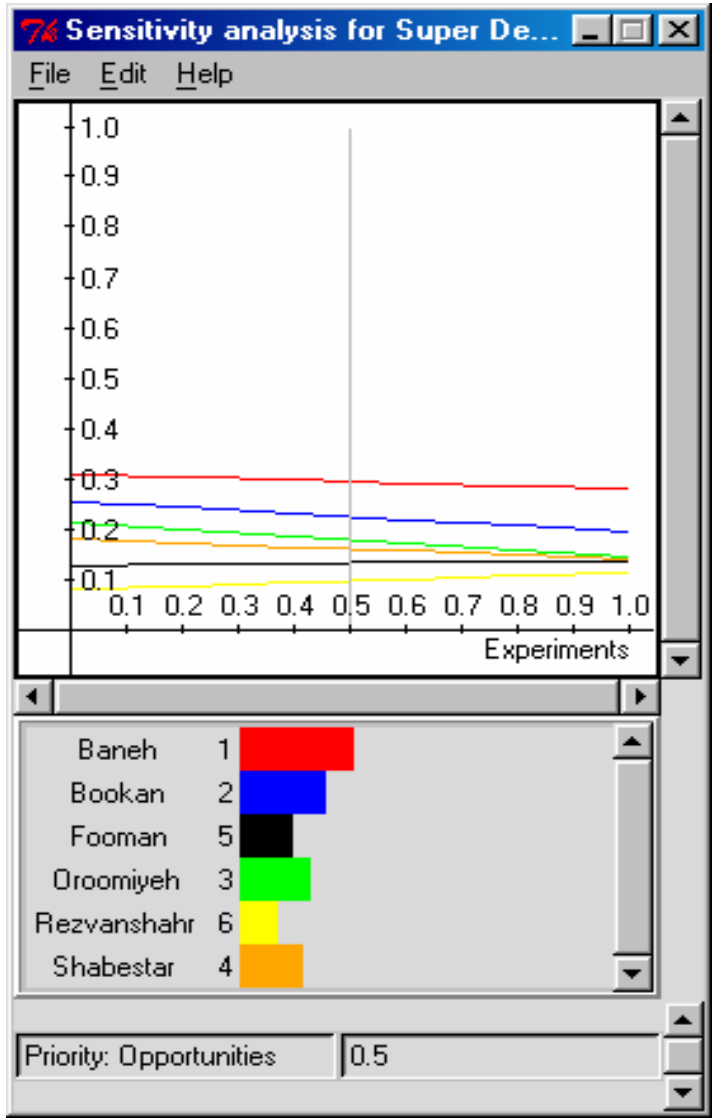

\section{References}

Saaty T., (1999) Decision Making for Leaders, RWS Publications, 4922 Ellsworth Avenue, Pittsburgh, PA 15213.

Saaty T., (2001a) Decision Making with Dependence and Feedback:The Analytic Network Process, RWS Publications, Pittsburgh, PA.

Saaty T. and Y. Cho, (2001b), "The Decision by the US Congress on China's Trade Status: a Multicriteria analysis", Socio-Economic Planning Sciences, 35, 243-252, Elsevier ScienceLtd.

Saaty T., (2001c) Decision Making in Complex Environments, The Analytic Network Process for Decision Making with Dependence and Feedback, University of Pittsburgh.

Haksever C., Render B., Russell R.S. and Murdick R.G., (1990) Service Management and Operations, Prentice Hall, Upper Saddle River, Newjersey.

Krajewski L.J., and Ritzman L.P., (1999) Operations Management, Strategy and Analysis, Addison Wesley, Massachusetts.

Chase, R.B., Aquilano N.J., and Jacobs F.R., (1998) Production and Operation Management, Manufacturing and Sevices, McGraw-Hill, Boston. 